\title{
Lessons from Corporate Influence in the Opioid Epidemic: Toward a Norm of Separation
}

\author{
Jonathan H. Marks
}

Received: 6 June 2019 / Accepted: 6 May 2020 /Published online: 13 July 2020

(C) Journal of Bioethical Inquiry Pty Ltd. 2020

\begin{abstract}
There is overwhelming evidence that the opioid crisis - which has cost hundreds of thousands of lives and trillions of dollars (and counting) - has been created or exacerbated by webs of influence woven by several pharmaceutical companies. These webs involve health professionals, patient advocacy groups, medical professional societies, research universities, teaching hospitals, public health agencies, policymakers, and legislators. Opioid companies built these webs as part of corporate strategies of influence that were designed to expand the opioid market from cancer patients to larger groups of patients with acute or chronic pain, to increase dosage as well as opioid use, to downplay the risks of addiction and abuse, and to characterize physicians' concerns about the addiction and abuse risks as "opiophobia." In the face of these pervasive strategies, conflict of interest policies have proven insufficient for addressing corporate influence in medical practice, medical research, and public health policy. Governments, the academy, and civil society need to develop counterstrategies to insulate themselves from corporate influence and to preserve their integrity and public trust. These strategies require a paradigm shift-from partnerships with the private sector, which are ordinarily vehicles for corporate influence, to a norm of separation.
\end{abstract}

\section{J. H. Marks $(\bowtie)$}

Bioethics Program, Pennsylvania State University, 332 Pond Building, University Park, PA 16802, USA

e-mail: marks@psu.edu
Keywords Opioids · Corporate influence .

Public-private partnerships - Conflict of interest .

Institutional integrity $\cdot$ Public health ethics

The opioid epidemic has claimed the lives of more than 400,000 Americans in the last two decades (CDC 2019a). It has devastated families, destroyed entire communities, and drained the resources of social services. Opioid addiction and deaths impose societal costs that, in the United States alone, are now measured in the trillions of dollars (CEA 2017, 2019), with many of these costs falling on underfunded local and state government agencies. In recent months, much evidence has emerged demonstrating the ways in which opioid companies' strategies of influence fuelled the crisis. Companies built relationships with a variety of individuals and institutions: physicians, professional societies, patient advocacy organizations, research universities, public health agencies, and legislators. Although the impact of these strategies has been most closely observed in North America, their reach is international.

Previous analyses of corporate influence in the pharmaceutical sector make clear that the opioid companies' strategies are not entirely novel (see, e.g., Applbaum 2009). Some of the leading case studies should have been cautionary tales because they also involved prescription medicines for the treatment of pain (see, e.g., Steinman et al. 2006; Ross et al. 2008). A number of corporate strategies were honed within the drug and medical device sector-for example, hiring "medical education and communication companies" (or MECCs) 
to shape the evidence required for the approval and promotion of new products and recruiting physicians as "key opinion leaders" (KOLs), a title designed to be psychologically rewarding, and paying them to deliver scripted promotional presentations to their peers (Sismondo 2018; Sah and Fugh-Berman 2013). But many strategies were developed with the advice and guidance of the kinds of entities - public relations, management consultancy, and crisis management firmsthat were previously hired by tobacco companies and other industries to cast doubt on the harms caused by their products or commercial practices (see, e.g., Michaels 2008; Armstrong 2019; Michaels 2020). These strategies are both extensive and comprehensive, involving webs or networks of relationships with government, the academy, and civil society (Marks 2019a). Although relationships are widespread at institutional levels, media attention tends to focus on individualsmost commonly, excoriating doctors and researchers for failing to disclose that they have industry-related financial conflicts of interest.

The focus on "naming and shaming" individuals, even when warranted, threatens to downplay or ignore a systemic problem: institutional and societal cultures and practices that embrace partnership with industry and, wittingly or unwittingly, promote companies' products, increase brand loyalty, burnish corporate reputations, defuse support for the regulation of companies' products and marketing practices, and reinforce the framing of public health problems and their solutions in ways that are least threatening to the commercial interests of those companies (Marks 2019a). Nowhere is this more evident than in the origins of and responses to the opioid crisis, where collaborative efforts to address pain management - an important and historically neglected problem in medicine and public health - have profoundly exacerbated another major public health challenge, addiction (see, e.g., Meier 2018; Macy 2018; McGreal 2018).

Opioid companies' strategies were designed to expand the prescribing of opioids from terminal cancer patients to a larger and more lucrative population: patients with non-cancer-related acute and chronic paindespite lack of evidence of efficacy in relation to the latter. Companies promoted-some would say pushed - higher doses of opioids in order to increase profits further, while downplaying the risks of addiction and abuse. In addition, companies framed both doctors and patients as the problem. Physicians who had legitimate concerns about the addictive properties of opioids were characterized as having "opiophobia." This term, coined by Purdue Pharma, the manufacturer of arguably the most well-known prescription opioid, OxyContin, later found its way into guidelines of the World Health Organization (WHO) (Clark and Rogers 2019). These guidelines remained in effect for the better part of a decade until they were "discontinued" by the WHO in June 2019 in the wake of revelations of corporate influence (WHO 2019). Patients who became addicted were, of course, not characterized as victims of an aggressive marketing and public relations strategy. When Richard Sackler was president of Purdue Pharma in 2001, he urged colleagues to blame and "hammer" patients, describing them contemptuously as "abusers," "culprits," and "reckless criminals" (Zezima and Bernstein 2019).

Most of the media attention has focused on Purdue Pharma - and on members of the Sackler family who are major shareholders. ${ }^{1}$ However, it is important to keep in mind that this company was only one of several drug companies that promoted their opioids by building webs of relationships with a variety of public health agencies, academic institutions, and public health NGOs, as well as thousands of individual health professionals. A recent trial in Oklahoma shed light on the activities of Johnson \& Johnson, a family of companies that has not only sold its own opioids but also supplied the active ingredients to several other opioid companies, including Purdue Pharma (Hoffman 2019a, 2019b). For that reason, Johnson \& Johnson had an additional incentive to engage (and did engage) in the unbranded promotion of opioids. The criminal trial of the former executives of another company, Insys, also shed light on its fraudulent marketing practices (Emanuel and Thomas 2019). We know more about the "webs of influence" woven by these companies than about the strategies of other companies that have been more successful, thus far, at keeping evidence out of the public domain - often by settling cases before they go to trial. But there is clear evidence that aggressive promotion strategies were widespread, to varying degrees, across the opioid industry (Horwitz et al. 2019). Building on other recent work (Marks 2019a, 2019b, 2019c), I will

\footnotetext{
${ }^{1}$ The Sackler family's arts philanthropy has attracted much attention. I focus my analysis here on relationships with entities in health and policy spheres because they appear to have most directly contributed to the opioid crisis. But I recognize that arts philanthropy also merits ethical scrutiny that I cannot provide in the space permitted.
} 
tease apart some strands of the known webs of influence of the opioid industry before reviewing the cumulative effects and exploring the ethical and policy implications.

\section{Influencing Physicians and Health Professionals}

Arthur M. Sackler died in 1987, long before Purdue Pharma's 1996 launch and subsequent aggressive marketing of its leading opioid brand, OxyContin. But the roots of pharmaceutical marketing to physicians go back seven decades (Greene and Podolsky 2009), and Sackler was a vital rhizome (Podolsky, Hertzberg, and Greene 2019). He may not have invented the practice of medical marketing but, as the Medical Advertising Hall of Fame put it: "No single individual did more to shape the character of medical advertising than the multi-talented Dr. Arthur Sackler. His seminal contribution was bringing the full power of advertising and promotion to pharmaceutical marketing" (Podolsky 2015, 25). The extent and efficacy of opioid marketing in recent years has arguably gone far beyond Sackler's wildest dreams or, more charitably, his worst nightmares.

Between 2014 and 2015, roughly one in seven physicians in the United States received opioid-related gifts from pharmaceutical companies (Hollander et al. 2019); another analysis of a similar period puts the figure for family physicians even higher at one in five (Hadland, Krieger, and Marshall 2017). During this time, physicians wrote more than seventy opioid prescriptions per year for every hundred Americans (CDC 2019b). Unsurprisingly, studies have found the receipt of payments from opioid companies is associated with increases in physicians' prescribing rates (Hadland et al. 2018; Hollander et al. 2019). That is, of course, the reason drug companies engage in such practices, and similar effects have been found in relation to a variety of other prescription drugs. But disturbing recent research reveals why, in the case of opioids, the resulting increase in prescribing is especially problematic. A study of 67,507 physicians in 2,208 counties across the United States between 2013 and 2015 concluded that drug companies' marketing of opioids to physicians was associated with not only increased opioid prescribing but also elevated mortality from overdoses (Hadland, Rivera-Aguirre, and Marshall 2019). More troubling still, court documents recently filed by the AttorneyGeneral of Massachusetts allege that doctors who met with Purdue Pharma drug reps were ten times more likely to have prescribed opioids to patients who later died of an overdose than physicians who prescribed opioids without having met the company's drug reps (Attorney-General of Massachusetts [A.G. Mass.] 2019; Joseph 2019a).

In February 2018, Purdue Pharma said it would stop marketing opioids to physicians (Poston 2018). But we should not derive any comfort from these kinds of voluntary commitments. First, the Massachusetts court documents make clear that the company continued its aggressive marketing strategy for at least a decade after it pleaded guilty in 2007 to misleading physicians and patients by downplaying the risks of addiction and abuse of its leading brand, OxyContin (Meier 2007). That strategy was complemented by an insidious kickback scheme: Purdue Pharma paid a technology company to generate prompts in electronic health records (EHR) software encouraging physicians to prescribe more opioids (Farzan 2020). Second, a consortium of companies known as Mundipharma, also owned by members of the Sackler family, has been making efforts to expand opioid markets internationally. While some of Mundipharma's apparent practices in China go beyond what has been alleged in the United States, the broad strategy of downplaying the risks of addiction and abuse clearly resembles Purdue Pharma's North American strategies (Kinetz 2019). As former U.S. Food and Drug Administration (FDA) commissioner David Kessler observed, "It's right out of the playbook of Big Tobacco. As the United States takes steps to limit sales here, the company goes abroad" (Ryan, Girion, and Glover 2016, I99).

Purdue Pharma is just one of several opioid manufacturers that have been making payments to physicians (see, e.g., Hollander 2019) - and it is not the only company to have engaged in the aggressive marketing of opioids (Horwitz et al. 2019). A U.S. Senate report describes in some detail how another company, Insys, engaged in similarly aggressive practices (Homeland Security and Government Affairs Committee [HSGAC] 2018b). The report revealed that executives emphasized to their sales reps the importance of "owning" physicians and of "holding the customer [that is, the physician] accountable" when they failed to sustain or increase sales of Subsys, a fentanyl brand. The company's new CEO informed the Senate Committee that the company had learned from past 
mistakes and replaced most of its sales force. But in the wake of multiple indictments, congressional investigations, civil lawsuits, and much highly critical media attention (see, e.g., Woodson 2019), this is too little too late. It remains to be seen whether the conviction of several former Insys executives for fraudand the prospect of imprisonment for several yearswill change corporate cost-benefit analyses in ways that previous fines on companies have not (Emanual and Thomas, 2019; Raymond 2019; Thomas 2020).

\section{Influencing the Academy: Universities and Academic Medical Centres}

Several academic institutions and universities received donations from opioid companies, and corporate philanthropy sometimes dove-tailed with individual philanthropy (Joseph 2019b; Associated Press 2019). Notably, both Purdue Pharma and members of the Sackler family made gifts to universities and teaching hospitals. While the history of this philanthropy predates the launch of OxyContin, the gifts intensified thereafter. In 1980, three Sackler brothers established the Sackler Graduate School of Biomedical Sciences at Tufts University (A.G. Mass. 2019). In 1999, three years after the launch of OxyContin, family members made a more targeted gift to Tufts to establish a Master's of Science in Pain Research, Education, and Policy (A.G. Mass. 2019). In 2002, Purdue Pharma also gave \$3 million to the pain centre at Massachusetts General Hospital (MGH), which was renamed the "MGH Purdue Pharma Pain Center" (AAAS 2002).

Remarkably, academic institutions continued to accept donations from and build relationships with Purdue Pharma after the company and several of its executives had pleaded guilty in 2007 to misleading doctors and patients about the addiction risks of OxyContin (Meier 2007). A recent independent review (commissioned by Tufts) found "no evidence of any meaningful attempt by Tufts to reconsider its relationship with, or distance itself from, the Sacklers or Purdue" in the wake of the guilty plea-or at any time prior to the publication in autumn 2017 of highprofile magazine articles severely criticizing Purdue and members of the Sackler family (Yurko and Remz 2019, 10; Keefe 2017).

Tufts was not the only academic institution to accept gifts from Purdue Pharma after the 2007 guilty plea. In
2010-2011, MGH received an additional \$3 million gift for its pain centre. Around this time, the company also made gifts to promote opioids in programmes at a dozen institutions in Massachusetts alone. These gifts included five-figure sums to Boston University, Northeastern University, and Massachusetts College of Pharmacy (A.G. Mass. 2019). The donations made sense from the donor's perspective - at a time when opioid companies were coming under greater scrutiny, these relationships gave Purdue Pharma opportunities not only to influence students and doctors but also to burnish the company's reputation. But these gifts were extremely perilous to the integrity of and public trust in the recipients - as well as patient health.

Contemporaneous documents make these perils strikingly clear. In 2014, when Purdue's medical liaison staff succeeded in getting two "unbranded curricula" approved for teaching Tufts studentsdescribed by the university as "the next generation of leaders in the field of pain"- the accounts team congratulated their colleagues for "penetrating this account" (A.G. Mass 2019, I[285). In 2015-2016, the Tufts University School of Medicine decided not to assign as the "Common Book" for all incoming medical students, Sam Quinones' Dreamland (2006), "in significant part" because the book criticized Purdue Pharma for its role in the opioid crisis and there was a "desire to avoid controversy" in the donor relationships with Purdue Pharma and the Sackler family (Yurko and Remz 2019, 23). The following year some students became upset after a lecture by a senior employee of Purdue Pharma with an adjunct appointment at Tufts (who had been giving occasional lectures on opioids for a decade). They complained that he was "sweeping the opioid crisis under the rug" and was "an apologist for the pharma industry" (Yurko and Remz 2019, 20).

There are also thousands of pages of emails, memoranda, and other contemporaneous documentssummarized in the complaint of the Attorney-General of Massachusetts made public in 2019 - that reveal how Purdue Pharma's relationships with academic institutions provided opportunities to influence research, curricula, speaker series, and other events. These opportunities were enhanced by the appointment of Purdue executives and employees to faculty and advisory boards, as well as by regular contact with these individuals (A.G. Mass. 2019). In addition, one recent estimate puts the total gifts from the Sackler family and its 
foundations to universities in the United States, the United Kingdom, and elsewhere in excess of $\$ 60$ million during the last five years (AP 2019). ${ }^{2}$

In public health, corporate strategies of influence tend to involve public health NGOs, as well as academic institutions. And, perhaps unsurprisingly, the leadership of these institutions often overlaps. For example, one of the founders of the Tufts pain initiative also served as president of the American Academy of Pain Medicine (a medical professional association) and on the board of the American Chronic Pain Association (a patient advocacy organization) (Joseph 2019c). As a result, pharmaceutical companies could influence professional associations and advocacy groups without making additional financial contributions to those organizations. Nevertheless, opioid companies also targeted civil society groups, and gifts to these entities were a central component of several opioid companies' strategies of influence.

\section{Influencing Patient Advocacy Organizations, Professional Societies, and Other Civil Society Groups}

Industry funding of patient advocacy organizations (PAOs), professional societies, and other health-related NGOs more broadly has become widespread (McCoy et al. 2017; Rose et al. 2017; Aaron and Siegel 2017). These organizations often face tight financial constraints and, not surprisingly, pharmaceutical companies are more than happy to "help out." Although a corporate donation may be a drop in the ocean of business revenues and profits, the gift can be the main - or onlything keeping the recipient afloat (Marks 2019a). The contributions of opioid companies to PAOs and health professional associations have been consistent with practices in the pharmaceutical sector more broadly. A U.S. Senate report revealed that five opioid manufacturers gave $\$ 9$ million to fourteen patient advocacy organizations and health professional organizations over the five-year period 2012-2017 (HSGAC 2018a). Purdue and Insys were the largest donors by far, giving in excess of $\$ 4$ million and $\$ 3$ million respectively. While the U.S. Pain Foundation received more than

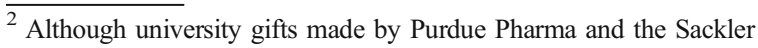
family have attracted the most public scrutiny, the conviction of the former CEO of Insys, John Kapoor, drew attention to his gifts to the University of Buffalo's School of Pharmacy and ultimately led to the removal of his name from the school's building (McNeil 2019).
}

any other organization - in excess of $\$ 2.9$ millionseveral other groups were also dependent on funding from opioid companies. Notably, the Academy of Integrative Pain Management received more than $\$ 1$ million and, when this funding dried up in the wake of the U.S. Senate report, the organization closed because it lacked sufficient funds to maintain operations (Anson 2019). The American Pain Society received almost \$1 million from opioid companies, and it also dissolved in 2019 after facing lawsuits for its role in exacerbating the opioid crisis (McGreal 2019). It is notable that the organizations discussed in the report continued to accept opioid industry money after one of them, the American Pain Foundation, closed its doors in 2012 in the wake of an investigation revealing its dependence on opioid industry funding (Ornstein and Weber 2012).

Groups that received money from the opioid industry subsequently engaged in activities - including participation in policymaking processes - that protected and promoted the interests of their donors. As a result, some patient advocacy groups and health professional societies have been characterized as "front groups" for industry (e.g., Michaels 2020). But even when organizations are genuinely created to promote the interests of patients, they can be profoundly influenced by gifts from and relationships with corporate actors - as the ethnographic and behavioural science research on reciprocity makes clear. Reciprocity need not involve an explicit exchange (often called a quid pro quo); on the contrary, gifts can give rise to subtle reciprocity-which often manifests as a general disposition toward helping another (Marks 2019a). Companies understand and commonly exploit this to promote policies that protect their interests. A recent study concludes that corporations "strategically deploy charitable grants" to non-profit organizations so that the recipients will comment favourably in regulatory processes (Bertrand et al. 2018 , 1). The authors also found that this strategy is effective at promoting regulatory discussions more closely aligned with the companies' perspectives and commercial interests.

When the Centers for Disease Control and Prevention (the CDC) issued draft guidelines in 2016 recommending greater restraint in opioid prescribing, opposition was significantly higher among organizations that had received funding from the opioid industry (Lin et al. 2017). In addition, a number of groups that received opioid industry funding lobbied against legislation restricting opioid prescribing and produced their 
own guidelines downplaying the addiction risks (HSGAC 2018a). Recently released internal documents reveal that Purdue Pharma considered these kinds of guidelines to be "an effective tool for selling our products" (Ross 2019, I19). Influence on health-related NGOs is especially important because of the ways in which these bodies may, in turn, influence policymakers, policymaking, and the resulting policies.

A recent article in the $B M J$ expressed concern that the National Academies of Science, Engineering, and Medicine (NASEM) — an NGO established by federal statute with the express purpose of providing independent advice to the federal government in the United States-had received millions of dollars from several pharmaceutical companies (including opioid manufacturers), as well as gifts from members of the Sackler family (Schwab 2019). The article also expressed concern that members of NASEM panels, including one commissioned to advise policymakers on clinical practice guidelines for prescribing opioids, had received payments from opioid companies (in the form of research funding, consultancy fees, and advisory board retainers).

Representations from bodies that appear to be independent or - at the very least, that appear to be promoting the interests of patients - may be viewed with much less scepticism by public officials than representations coming directly from companies. But, once again, opioid companies left nothing to chance. Just as they made direct payments to PAOs and health professional associations to bolster indirect influence arising from relationships with leading health professionals, companies also reinforced indirect influence of public officials, legislators, and policymakers by making contributions to political campaigns and public health initiatives.

\section{Influencing Public Health Officials, Legislators, and Policymakers}

According to the Center for Public Integrity (CPI) and the Associated Press, between 2006 and 2015, opioid companies spent $\$ 880$ million on lobbying and campaign contributions - dwarfing the $\$ 4$ million spent by groups advocating limits on opioid prescribing, and (more surprisingly) exceeding by a factor of eight the gun lobby's political spending (CPI 2016a, 2016b). The CPI found that the industry and its allies contributed to roughly 7,100 candidates for state-level offices, employing on average 1,350 lobbyists a year, covering all state capitals. Another study examined campaign contributions to members of the U.S. House and Senate committees charged with responsibility for leading the legislative branch's response to the opioid crisis. It found that, during the two-year election cycle ending in November 2016, almost 90 per cent of the members of the House committee (forty-nine of fifty-five), and close to two-thirds of the members of the Senate committee (fifteen of twenty-three) had received money from political action committees (PACs) that were associated with firms under investigation by state and federal officials for exacerbating the opioid crisis (McCoy and Kanter 2018). Once again, while shocking, this was reasonably predictable. We should anticipate that opioid companies would try to influence legislators to the full extent that the law allows in their efforts to prevent legislators from undermining their commercial interests when responding to the opioid crisis. And we should also expect that these companies' strategies of political influence would not be confined to lobbying and campaign contributions.

Another key element in the opioid companies' strategies - consistent with corporate strategies in other sectors such as food and soda-is to engage in partnerships with government agencies. These are often termed "public-private partnerships" or, when academic institutions and public health NGOs participate too, "multistakeholder initiatives" (Marks 2019a). Sometimes, it is the corporate actors that initiate these relationships; at other times, the public bodies do so. In 2017, the National Institutes of Health (NIH) launched a "public-private initiative" to address the opioid crisis. More than one-third of the participants at its first two meetings in June 2017 were executives of drug companies, device manufacturers, or other industry actors (NIH 2019). They included representatives of Purdue Pharma and Johnson \& Johnson-which, along with its subsidiary, Janssen Pharmaceuticals, was also a defendant in opioid litigation. Notably, when the NIH launched the partnership initiative, it made no mention of the role that its "private partners" played in creating or exacerbating the opioid crisis in the "special report" written by the directors of the NIH and the National Institute of Mental Health (NIMH) and published in the New England Journal of Medicine (Volkow and Collins 2017). On its website, the NIH director used the passive voice to avoid pointing the finger at drug companies: "The belief that people with pain would not become 
addicted to opioids was promoted 20 years ago in the medical community" (Collins 2017, I[2). This statement begs the question: promoted by whom? It is not hard to see why Collins avoided that question. Self-censorship is common among the recipients of gifts and among public bodies participating in partnerships (Marks 2019a). The NIH clearly did not want to alienate the drug companies with which it wished to partner.

While the NIH considered Purdue Pharma a "partner," the company wanted to make sure that the broader public did so too. It ran full-page advertisements in the New York Times (among others) that concluded with these words: "We want everyone engaged to know that you have a partner in Purdue Pharma. This is our fight too" (Purdue Pharma 2018, I5). At the same time, the company appears to have been engaged in a very different kind of battle - an internal debate about whether or not to continue disputing the claim that OxyContin can be addictive even when taken as directed. On July 19, 2018, Purdue ran another full-page "advocacy ad" in the Washington Post stating that the company was "acutely aware of the public health risks opioid analgesics can create, even when taken as prescribed" (Schulte 2018, $\Phi[2$, emphasis added). But less than a week later, when the company reran the advertisement, it deleted the words "even when taken as prescribed." In addition, while the company was being described by the NIH as a "partner"- and while it was positioning itself as a partner-Purdue Pharma was also working on plans to expand the opioid market, including the market for therapies to treat opioid addiction resulting from the company's own aggressive opioid marketing strategies (A.G. Mass. 2019).

To be clear, the efforts of the opioid industry to influence policymakers and prescribers were not limited to the United States. Investigative journalists have uncovered similar efforts to exploit international markets (Ryan, Girion, and Glover 2016; Kinetz 2019). And these efforts appear to have increased as opioid prescribing came under increasing scrutiny in the United States. Global promotion has been spearheaded by Mundipharma, a consortium of companies with offices in more than 120 countries. A recent congressional report produced by the offices of two U.S. representatives outlined the ways in which this consortium appears to have successfully influenced at least two WHO policy documents related to opioid prescribing _ including 2012 guidelines that address pain management in children (Clark and Rogers 2019; WHO 2011, 2012). In several ways, these guidelines (which were discontinued by the WHO in 2019 in the wake of the congressional report) were remarkably consistent with Purdue's marketing strategies. For example, they embraced Purdue's characterization of doctors' concerns about prescribing opioids as "opiophobia." The guidelines also stated that there is no maximum dose for opioidseven in the case of children. (Purdue Pharma and other opioid companies pushed broadly for higher doses, as they are significantly more lucrative than lower doses.) The congressional report also highlighted the role of patient advocacy organizations, professional associations, and industry-favourable articles published in their journals as avenues for indirect influence on the WHO (Clark and Rogers 2019).

\section{Corporate Influence: Coordinated, Concurrent, and Competitive Action}

Although Purdue Pharma has received considerable media attention in recent months for the aggressive marketing of opioids, it is important to keep in mind that several companies are alleged to have engaged in such practices. The picture that emerges is one of multiple corporations making gifts to and partnering with a variety of public health agencies, academic institutions, and health-related NGOs. These gifts and relationships were part of larger strategies that were intended to have, and did have, a number of interrelated effects - all of which served to increase the revenues and profits of the opioid companies. The strategies were designed to expand the base of patients who would be prescribed opioids from (often terminal) cancer patients to non-cancer patients experiencing either acute or chronic pain; to promote the acceptance of opioids as the drug of choice in such cases, despite the lack of evidence as to their efficacy (especially for chronic pain); to expedite the prescribing of opioids in place of other analgesics and pain therapies; to downplay the risks of addiction and abuse; to characterize doctors' concerns about addiction and abuse as "opiophobia"; to promote the view that opioids are not addictive when taken as directed; and to blame patients when they became addicted.

The success of the opioid companies in these respects was the result of both independent and coordinated action. Corporations may influence policymakers through both kinds of activity, and trade associations often play a major role in coordinating action to influence policy in the pharmaceutical sector. PhRMA (Pharmaceutical 
Research and Manufacturers of America), the main trade association representing pharmaceutical companies in North America, has coordinated an industry response to the opioid crisis. As two New York Times journalists recently put it, "PhRMA is trying to position the industry on the right side of a health crisis that many blame it for creating" (Corkery and Thomas 2018, I10). The article in which that observation was made raised legitimate concerns about PhRMA providing funding to the patient advocacy organization, Addiction Policy Forum. Of course, the trade association's support of this advocacy group is not an isolated relationship; it is part of the concerted strategy intended to influence the perceptions of policymakers, physicians, and patients (among others). Drug companies want us to see them as partners in developing solutions to the opioid crisis, rather than actors responsible for creating or exacerbating the crisis. Mirroring statements made by the NIH and the National Institute on Drug Abuse (NIDA), PhRMA issued its own press release announcing that it was "working to establish a public-private partnership" designed to "accelerate the development of innovative new treatments and therapies" (PhRMA 2017).

These are examples of what might be considered corporate coordination - collaborative efforts to influence policy and practice often mediated by a trade association. However, it is important to recognize that the independent actions of companies may also be highly influential, even when competitive. We saw above how five different opioid companies all made financial contributions to patient advocacy organizations and health professional associations related to pain management. To some extent, these activities might be regarded as concurrent - each company giving money with the intention of fostering an even more permissive attitude toward the use of opioids that would be reflected in the recipients' representations to policymakers. But some of these activities might be considered competitive to the extent that the company making the donation intended to generate more prescriptions for its opioids by "stealing" potential patients from its competitors. Recent court filings in Massachusetts, for example, provide evidence of the competitive strategies of Purdue Pharma (see A.G. Mass. 2019). But whether concurrent or competitive, the effect of these contributions was the same: to influence the public statements and representations of civil society groups so that they too favoured the relaxation of prescribing guidelines and downplayed the addiction and abuse risks. Competitive and coordinated corporate strategies of influence may occur simultaneously as well as sequentially. As manufacturers of opioids and suppliers of active ingredients to other opioid companies (Hoffman 2019a), the Johnson \& Johnson family of companies (which includes Janssen Pharmaceuticals) had an additional incentive to engage in both strategies. So, any counterstrategy intended to insulate governments, universities, and public health NGOs from corporate influence should also address both strategies.

The significance of these forms of influence becomes especially important when we consider the ethical challenges presented by public-private partnerships, which have become the dominant paradigm in public health. As I noted above, the NIH launched a "public-private initiative" in response to the opioid crisis, bringing together representatives of dozens of pharmaceutical companies. Policymakers often justify the practice of "engaging" with multiple competing corporations in a partnership initiative on the grounds that this ensures no single corporation receives preferential treatment. However, it is important to recognize the ways in which incorporating multiple powerful corporate actors from the same sector in a partnership can be ethically problematic. Bringing together multiple pharmaceutical companies can transform their concurrent actions into coordinated action - thereby magnifying the companies' influence. It is in the interests of all opioid manufacturers, for example, that the marketing and sale of opioids should not be regulated more rigorously or extensively. It is also in the interests of all pharmaceutical companies, whether or not they are currently manufacturing or selling opioids, for public health agencies to focus on pharmaceutical responses to pain management and opioid addiction.

\section{From Conflicts of Interest to a Norm of Separation}

The traditional lens for understanding and addressing corporate influence in medicine and public health has been conflicts of interest. The definition of conflict of interest most frequently employed in this context is the one adopted by the Institute of Medicine (now the National Academy of Medicine) in the U.S.: "a set of circumstances that creates a risk that professional judgment or actions regarding a primary interest will be unduly influenced by a secondary interest" (Lo and 
Field 2009, 46). ${ }^{3}$ But framing the problem of corporate influence as financial conflicts of interest tends to have two consequences. First, while conflicts of interest can be defined broadly to include institutional conflicts, attention is usually focused on individuals rather than institutions - for example, physicians who receive payments from drug companies, rather than academic medical centres or universities that might have equally problematic relationships with drug companies. Notably, a recent independent review commissioned by Tufts to explore the university's relationships with Purdue Pharma and the Sackler family found that, while there were policies addressing individual conflicts of interest, the university did not have - and needs to establish - a comprehensive institutional conflicts of interest policy (Yurko and Remz 2019). Investigative journalism also tends to highlight individual physicians who have failed to disclose financial conflicts of interest arising from their relationships with corporate actors (e.g., Ornstein and Thomas 2018); less attention has been paid to institutional practices and cultures that might promote such behaviours. Conflicts of interest at the institutional level tend to be poorly managed, if they are managed at all, and rarely are they eliminated (Marks 2019a).

Once conflicts of interest have been recognized as a problem, the most commonly touted policy solution is disclosure of the conflict. The Physician Payments Sunshine Act (PPSA) - part of the Affordable Care Actplaces the responsibility on drug and device manufacturers to disclose their payments to physicians and teaching hospitals (Richardson 2014). Section 6111 of the Substance Use-Disorder Prevention that Promotes Opioid Recovery and Treatment for Patients and Communities (SUPPORT) Act of 2018 — entitled "Fighting the Opioid Crisis with Sunshine"- expands the scope of transactions covered by the PPSA to include payments to physician assistants, nurse practitioners, clinical nurse specialists, certified registered nurse anaesthetists, and certified nurse-midwives - commencing in 2022. Several scholars have also explored whether this requirement should be further extended to include payments

\footnotetext{
${ }_{3}^{3}$ For a thoughtful critique of this definition, see Rodwin 2018. Rodwin argues that the Institute of Medicine's 2009 definition of conflicts of interest "neglects the actor's compromised loyalty to the party or mission she is supposed to serve" (70) and that, by referring to conflicts between primary and secondary interests rather than conflicts between obligations and interests, this definition "diminishes the conflict's significance" (70). Rodwin also expresses concern that "[e]fforts to include so-called intellectual or nonfinancial conflicts as conflicts of interest blur the concept" (75).
}

made to patient advocacy organizations (e.g., McCoy 2018; Kanter 2018), and in October 2018, Senator McCaskill introduced a bill to this effect shortly before she lost her seat in the U.S. Senate.

Disclosure of financial conflicts of interest with corporate actors is necessary but not sufficient to address the systemic problem of corporate influence. It is the "ethical floor" as Bachynski and Goldberg $(2018,182)$ put it - the minimum, but far from all, that is required. Disclosure and other measures to promote transparency help reveal the extent of the problem of corporate influence. But we cannot and should not rely on such approaches to neutralize corporate influence. When policies primarily promote disclosure of conflicts instead of their elimination, there is a danger that they may exacerbate the problem of corporate influence - particularly when they lead policymakers and the relevant publics to believe (mistakenly) that problematic influence has been addressed. Several scholars have rightly expressed concern that disclosure, while necessary, might "crowd out" more effective measures to address corporate influence, including the elimination of relationships giving rise to financial conflicts of interest (e.g., Cain, Loewenstein, and Moore 2005; Loewenstein, Cain, and Sah 2012; Chambers 2017; Sah 2019; Marks 2019a; Kanter and Loewenstein 2019; Goldberg 2019; Marks 2020). This concern is especially acute in the case of the opioid crisis - fighting the crisis will require more than simply expanding the categories of recipient whose payments from opioid and other drug companies are subject to mandatory disclosure.

Given the evidence of the impact of interactions with drug reps on physicians' opioid prescribing and on opioid-related deaths, there is a compelling case that the best way to protect patients and insulate physicians from such influence is to prohibit these interactions. Disclosure rather than elimination of these relationships places the burden of addressing this systemic problem on patientsindividuals who are least equipped to tackle it and, worse still, are being harmed by it (see also Kanter and Loewenstein 2019). Notably, the vast majority of patients have not even begun to discharge that burden - they remain unaware of whether their doctors have received payments from drug companies, even though this information has been publicly available on the internet for several years (Kanter et al. 2019). But even if patients access this information - or if it is provided directly to them by their physician or the physician's office (Rose et al. 2019) —we cannot assume they will understand why it matters. We should certainly not expect them to 
be familiar with the relevant social science-including scholarship exploring the limitations and potential adverse effects of disclosure (e.g., Cain, Loewenstein, and Moore 2005; Lowenstein, Sah, and Cain 2012; Sah 2019). Yet another burden on patients resulting from disclosure is what some scholars call "insinuation anxiety"-although patients may want to act on the disclosure, they may be afraid to signal distrust to their physician (Loewenstein, Cain, and Sah 2011; Sah 2016; Sah, Loewenstein, and Cain 2019). And, even if patients are willing to act, they may not have the time or resources to find another physician they trust. This is a great deal to ask of any patient, let alone one in severe pain.

Disclosure of the opioid industry's relationships with universities, academic medical centres, and teaching hospitals, as well as individual researchers is also necessary, but not sufficient, if we are to address the influence of the opioid industry on medical research and education. We should bear in mind that many of the relationships were not a secret-for example, when Purdue Pharma gave a \$3 million gift to Massachusetts General Hospital (MGH) in 2002, its centre was named the "MGH Purdue Pharma Pain Center." Several metaanalyses have shown that industry funding of medical research tends to produce more favourable findings for the industry sponsor (see, e.g., Lundh et al. 2017; Bekelman, Li, and Gross 2003). Given that these analyses are based on studies that disclose their industry funding, it is clear that disclosure in this context does not serve to neutralize the bias.

In addition to the impact on research findings and the interpretations of those findings, industrysponsored research influences the kinds of questions that researchers explore (and those they neglect or ignore) and the ways in which those questions are explored (Marks 2019a, 75-78). Research agenda distortion - which is not eliminated by the disclosure of the relationships that contribute to the distortioncan be both subtle and profound. In the case of the opioid crisis, it triggered an expansion of the use of opioids to non-cancer patients, and it continues to lead to an emphasis on pharmacological solutions to both pain management and addiction. I am not suggesting that pharmacological solutions have no place. But, if we are serious about solving these public health challenges, we must be prepared to explore all potential solutions, including those that may be inimical to the commercial interests of pharmaceutical companies.
It would certainly have been important for the CDC to know that many of the patient advocacy organizations and medical professional associations that were objecting to its draft guidelines (calling for more restraint on opioid prescribing) had received funding from opioid companies. This was significant information, whether or not the groups were dependent on industry funding (and some clearly were). Lack of dependence is not the same as independence. ${ }^{4}$ So the disclosure of patient advocacy groups' and medical professional associations' financial relationships is clearly necessary. But disclosure alone will not address the systemic problem that arises when, as is so often the case, most of the relevant public health NGOs related to a particular health problem receive funding from industry actors with a vested interest in the solution to that problem. ${ }^{5}$ Policymakers are then left with the unenviable task of having to decide whether to ignore these entities' representations entirely or to accord them less weight — and, in either case, whether to do so across the board, or only when these groups' representations align with the interests of powerful corporate actors operating in the same space. And, more fundamentally, policymakers lack what they really need - access to the full range of views and interests of patients that are truly independent of the views and interests of industry.

Turning now to public health agencies and legislators, once again we see that disclosure of financial relationships is necessary but not sufficient to address the problem of corporate influence. Some information on campaign contributions is already in the public domain. For example, the Federal Elections Commission in the United States maintains a database of campaign finance contributions from political action committees (PACs). (This database, available at https://www.fec.gov, is the one on which McCoy and Kanter 2018 relied to assess the industry ties of the House and Senate Committees charged with leading the

\footnotetext{
${ }^{4}$ Physicians are not dependent on drug companies for pens and mugs - they can afford to buy their own! But these small gifts influence them nonetheless. See, e.g., Sah and Fugh-Berman 2013; Lo and Grady 2017.

${ }^{5}$ Although widely publicized investigations revealing opioid company payments to PAOs and health professional associations led to withdrawals of funding and, in a few cases, to the recipient organizations ceasing to operate, industry funding of patient advocacy groups remains pervasive. One recent study found that 83 per cent of the 104 largest groups received funding from drug, device, or biotechnology companies (McCoy et al. 2017). We should not expect disclosure alone to lead to the widespread elimination of these relationships, especially if the pervasiveness of these relationships reinforces the (problematic) view that they are acceptable or unavoidable.
} 
response to the opioid crisis.) We do not know the full extent of campaign contributions by opioid companies because hundreds of millions of dollars in campaign contributions are made via "superPACs" that shroud the origin of the funds. Greater transparency in relation to "dark money" is clearly important, but campaign contributions and lobbying can still influence legislators even when they are disclosed - as congressional voting records make clear (see, e.g., the website of the Center for Responsive Politics, https://www.opensecrets.org). The solution, of course, would be to take corporate money - including opioid industry funds - out of politics (see, e.g., Lessig 2015). A detailed consideration of campaign finance reform is, of course, beyond the scope of this paper. But I will address another powerful vehicle for corporate influence: close relationships between public health agencies and opioid companies.

After the director of the NIH announced the "publicprivate initiative" to address the opioid epidemic (discussed above), he commissioned a working group to explore the ethical issues. The working group based its recommendations on concerns about "real or perceived conflicts of interest" (NIH Working Group 2018). The group stated that it was "preferable" that public funds be used from this initiative, but it only recommended a bar on industry funding where an opioid company was engaged in "litigation of concern" related to the opioid crisis. The advisory group recommended that, in other cases, money provided by industry actors should be "without conditions." Even when companies are excluded from funding due to litigation, the working group said it would not only permit but encourage "in-kind" industry contributions to the partnership. In response to the group's report, the director of the NIH said that he "fully embrace[d]" the recommendation that the NIH should address the crisis with government, not industry, funds (Collins 2018). He also said that any partnerships in this initiative would be "done with the utmost transparency." These assurances, however, do not address all the ethical concerns.

First, influence can occur when there are no formal conditions (or "strings") attached - in fact, reciprocity often makes such conditions entirely unnecessary. Second, reciprocal effects are not confined to cash payments; they may be triggered by the receipt — or mere anticipation of the receipt - of "in-kind contributions," whether goods, services, or anything else of value (Marks 2019a). And third, transparent relationships may still be extremely influential. As I emphasized above, policymakers cannot and should not rely on transparency to eliminate corporate influence. In addition, such influence can distort policy agendas and reinforce the framing of two of our most pressing public health challenges, pain management and opioid addiction, in ways that are most likely to promote the commercial interests of the opioid industry and pharmaceutical companies more broadly (Marks 2019a, 78-81). This may explain the NIH's emphasis on the development of new pharmaceuticals to address pain management and addiction (Collins 2017, 2018).

It is tempting for public health officials to perceive an alignment of interests. At first glance, both the NIH and pharmaceutical companies might appear to have a shared interest in the development of effective nonaddictive pain medications. But that apparent alignment warrants interrogation (Marks 2019a). Even when a corporation engages in a business activity with the express aim of promoting health, its primary objective is the generation of profits from the sale of goods or services. The primary obligation of public health agencies is to protect and promote public health. Divergence between these objectives is inevitable and, at times, acute. A drug formulated to promote health (for example, by alleviating pain) may turn out to be less effective than anticipated or to have dangerous side-effects. In such cases, public health agencies have an obligation to ensure, at the very least, that health professionals and patients are made aware of these concerns. However, the drug company will have a powerful economic incentive to exaggerate the benefits of the drug, downplay the adverse effects, and promote sales for as long as possible to protect revenues - especially when profits dwarf potential financial penalties. We have seen precisely this scenario play out in the opioid crisis, and policymakers should be at pains to avoid its repetition.

Partnering with the pharmaceutical industry to address the opioid crisis courts serious public health hazards. The threat to public trust in government, the academy, and civil society groups is now readily apparent, too (Rose 2013; Marks 2019a). But there is another important reason for public health bodies to be wary of close relationships with the pharmaceutical industry: institutional integrity. A key component of institutional integrity is consistency-in particular, consistency among what an institution does (its practices), what it says it does (its mission), and what it is obligated to do (its purpose) (Marks 2017, 2019a). Public health agencies' and NGOs' 
relationships with the opioid industry have clearly served to undermine their public health mission and purpose - and, in turn, their integrity. The crisis is yet another painful reminder of the perils of partnership with any entity whose mission, purpose, or practices diverge fundamentally from those of one's own institution (Marks 2019a).

What the opioid crisis has also made clear, moreover, is that looking solely at the ethical implications of a single relationship between a public health agency, university, or public health NGO on the one hand, and a private-sector entity on the other, fails to take into account the systemic problem arising from corporate strategies that involve (as they almost invariably do) webs of influence with a variety of institutions in government, the academy, and civil society. Corporations do not build individual relationships in isolation; they develop strategies to engage with all these actors. But when each of these actors considers the ethics of "engagement," they tend only to focus on their own proposed relationship. Public health agencies, universities, and public health NGOs contemplating partnerships should be as attentive to webs of influence as the corporations that weave them.

Of course, being attentive to the webs of influence and their ethical and policy implications is resource intensive, and it cannot be a one-off enterprise either. Imagine you are the head of a public health agency. Yours may be the first public health agency to partner with corporation $\mathrm{X}$. But that corporation may be using its partnership with you as a pilot or test case that it will then use to "sell" the idea of partnership to another public health agency. Your public health agency would need to continue to be attentive to the relationships that corporation $\mathrm{X}$ is weaving with other public health agencies, universities, and NGOs - in addition to other private-sector entities (including trade associations and consultancy firms) with whom the corporation is collaborating in order to exercise influence. And your agency would need to be attentive to these relationships throughout its own relationship with the corporation. Such constant (or, at least, periodic) vigilance would require considerable additional resources. But the full extent of the webs of relations may not be apparent until far too late - as in the case of the opioid crisis. The safer and far more advisable course of action is simply to avoid these relationships - to move from the corporate partnership paradigm to a new norm: separation, instead of collaboration.

\section{Conclusion}

For years, courts sealed documents that would have revealed the role of corporate strategies of influence in the opioid epidemic (Lesser et al. 2019). News outlets have been challenging this practice, and the courts are finally unsealing documents from earlier opioid cases (Ross 2019). There has also been a plethora of new litigation against not only opioid manufacturers but also opioid distributorsincluding several high-street pharmacy chains as well as commercial distributors. In addition to thousands of civil cases against opioid companies (Gluck, Hall, and Curfman 2018), a few individuals have faced criminal charges (Gonzales 2019). Several former executives of one opioid manufacturer, Insys, were convicted of fraud, and recently received prison sentences (Thomas 2020). The verdict was swiftly followed by the company's agreement to pay $\$ 225$ million to settle its own fraud charges (Thomas 2019). In Oklahoma, a judgment of $\$ 465$ million was entered against the Johnson \& Johnson companies for creating a "public nuisance" that resulted not only from the group's promotion of its own brands of opioids but also from its promotion of opioids more generally and its supply of active ingredients to other opioid manufacturers (Hofman 2019a, 2019b). Purdue Pharma and Teva, which were also defendants in that case, settled shortly before the trial for $\$ 270$ million and $\$ 85$ million respectively (Silverman 2019). In order to avoid the landmark first federal trial, three commercial distributors and one manufacturer (again, Teva) also agreed in October 2019 to pay two Ohio counties \$260 million (Hofman 2019c). And in February 2020, Mallinckrodt Pharmaceuticals, the largest opioid manufacturer in the United States, announced a tentative agreement to pay $\$ 1.6$ billion to settle lawsuits brought by state and local governments for its role in the opioid crisis (Kaplan and Hoffman 2020).

Amid discussions of further settlements, two thousand cases wait in the wings (Hoffman 2020b). But we should not expect these cases and settlements to make good the economic losses resulting from the opioid epidemic (Hoffman 2019d, 2020a). Purdue Pharma and Insys have already filed for bankruptcy (Hals 2019a, 2019b). The judgement against Johnson \& Johnson will only cover one year of one state's abatement costs for an epidemic that will take decades to address. If efforts to reach a larger coordinated settlement are successful, they would be measured in the billions of dollars - far short of the trillions of dollars in the most recent cost estimates (Hoffman 2019c; CEA 2019). And any settlement would, of course, not bring back the hundreds of thousands of Americans who have 
died, nor would it restore the lives of the families and communities destroyed by the epidemic. If we are to prevent future loss of life, we need to supplement "backwardlooking" strategies based on establishing legal liability with some forward-looking ones (Young 2011; Marks 2017). Such forward-looking strategies must address the webs of relationships that served as vehicles for corporate influence and severely exacerbated the current crisis.

If the opioid epidemic has taught us anything, it is that governments, intergovernmental organizations, the academy, and public health NGOs need to be pre-emptive and proactive, developing comprehensive counterstrategies to insulate themselves from corporate influence. Whatever metaphor we use to describe corporate strategieswhether we characterize them as "webs" (Freudenberg 2014; Gornall 2015; Marks 2019a) or "tentacular" (Joseph 2019c) - the implications are the same: in order for counterstrategies to be effective, they cannot address individual relationships with industry actors in isolation. The opioid epidemic makes clear that individual institutions - whether governments, universities, or public health NGOs - are unlikely to be fully aware of the networks of relationships in which they are implicated until many years later. By that time, the damage may already have been done - as was undoubtedly the case with the opioid crisis. If we are to protect and promote public health, we will need a paradigm shift.

In order to bring about such a shift, we must first recognize that medicine and public health were not always so heavily dependent on corporate funding. The influx of this funding has burgeoned in the last few decades, as corporations increasingly and understandably recognized the opportunities for the promotion of their commercial interests that this affords them. But the relationships with industry that are now the norm were once frowned upon. This may not be readily apparent to the current generation of policymakers, researchers, practitioners, and others in medicine and public health - it may seem as though things have always been this way. But we need only turn to the work of the late Arnold Relman, former editor of the New England Journal of Medicine, in the early 1980s to be reminded that this is not the case. Drawing on President Eisenhower's warning about the "military-industrial complex," Relman expressed concern about the "new medicalindustrial complex," and cautioned that relationships with drug and device manufacturers had become "more pervasive, complex, and problematic" (Relman 1980, 963; Relman 1984, 1182).
Despite Relman's warnings, that trajectory has only increased during the last four decades. But it is not too late to change direction. Changing direction will require more than the withdrawal of donors' naming rights in response to criminal convictions, public outrage, or opprobrium (Barry 2019; McNeil 2019). First, public officials, academic administrators, and the leaders of public health NGOs must recognize that corporate influence in public health is a systemic problem, and they must speak out about that problem. If it is difficult for individual public officials or academic administrators to speak out on their own, they can collaborate with others by making a joint statement-for example, an open letter to the New York Times that makes clear why corporate partnerships are problematic and why more public funding to protect and promote public health is necessary. Government agencies may also collaborate with each other, instead of collaborating with industry, to address public health problems (Marks 2019a). Notably, the opioid litigation has involved considerable collaboration among states' attorneys-general. Working together, public health agencies can not only collaborate on addressing individual public health challenges, they can also develop strategies to wean themselves from industry funding. The same may be said for the academy and public health NGOs - including health professional associations (which have the power to influence norms and expectations for other institutions, as well as individual professionals). Although these institutions may not be able to restructure their funding strategies overnight, it is not unrealistic to expect them to develop a five- or ten-year plan.

Many proponents of corporate partnerships argue that we cannot afford to tackle the major challenges in public health without industry funding. But the opioid epidemic was fuelled by these very relationships, and it has cost us trillions of dollars. Given the human and financial toll, we simply cannot afford to carry on doing "business as usual" in public health.

Acknowledgments The author is extremely grateful to Michele Mekel and to all the student and faculty participants in the Penn State Bioethics Colloquium for their invaluable feedback on an earlier draft. This article also benefited from the author's discussions with several colleagues at other institutions - among them, Marc Rodwin, Sunita Sah, Genny Pham Kanter, Susannah Rose, and Lisa Cosgrove. He is also grateful to Quinn Grundy and another (anonymous) reviewer for their extremely helpful comments and suggestions. Please excuse any errors and omissions - final revisions to this piece were made during the COVID-19 pandemic. 


\section{References}

Aaron, D., and M. Siegel. 2017. Sponsorship of national health organizations by two major soda companies. American Journal of Preventive Medicine 52(1): 20-30.

American Academy of Arts and Sciences (AAAS). 2002. \$3 million gift from Purdue Pharma to support MGH pain program. AAAS Eureka Alert, February 7. https://www. eurekalert.org/pub_releases/2002-02/mgh-mg020702.php. Accessed December 1, 2019.

Anson, P. 2019. Pain Management Association shutting down. Pain News Network, February 2. https://www. painnewsnetwork.org/stories/2019/2/2/pain-managementassociation-closing-its-doors. Accessed December 1, 2019.

Applbaum, K. 2009. Getting to yes: Corporate power and the creation of a psychopharmaceutical blockbuster. Culture, Medicine, and Psychiatry 33(2): 185-215.

Armstrong, D. 2019. Inside Purdue Pharma's media playbook: How it planted the opioid "anti-story." Propublica, November 19. https://www.propublica.org/article/insidepurdue-pharma-media-playbook-how-it-planted-the-opioidanti-story. Accessed December 1, 2019.

Associated Press 2019. Top universities in US and UK took millions from Sackler family. The Guardian, October 4. https://www.theguardian.com/us-news/2019/oct/04 /universities-sackler-family-donations-opioids. Accessed December 1, 2019.

Attorney-General of Massachusetts. 2019. Commonwealth of Massachusetts v. Purdue Pharma L.P. et al. First Amended Complaint. January 31. https://www.documentcloud. org/documents/5715954-Massachusetts-AGO-AmendedComplaint-2019-01-31.html. Accessed February 7, 2019.

Bachynski, K.E. and D.S. Goldberg. 2018. Time out: NFL conflicts of interest with public health efforts to prevent TBI. Injury Prevention 24(3): 180-184.

Barry, E. 2019. Tufts removes Sackler name over opioids: "Our students find it objectionable." New York Times, December 5. https://www.nytimes.com/2019/12/05/us/tufts-sacklername-opioids.html. Accessed December 6, 2019.

Bekelman, J.E., Y. Li, and C.P. Gross. 2003. Scope and impact of financial conflicts of interest in biomedical research: A systematic review. JAMA 289(4): 454-465.

Bertrand, M., M. Bombardini, R. Fisman, B. Hackinen, and F. Trebbi. 2018. Hall of mirrors: Corporate philanthropy and strategic advocacy. NBER Working paper 25329 (December 2018). http://www.nber.org/papers/w25329. Accessed December 1, 2019.

Cain, D., G. Loewenstein, and D. Moore. 2005. The dirt on coming clean: Perverse effects of disclosing conflicts of interest. Journal of Legal Studies 34(1): 1-25.

Center for Public Integrity (CPI). 2016a. Pharma lobbying held deep influence over opioid policies. September 18. https://publicintegrity.org/state-politics/pharma-lobbyingheld-deep-influence-over-opioid-policies/. Accessed December 1, 2019.

2016b. Politics of pain: Drugmakers fought state opioid limits amid crisis. December 15. www.publicintegrity. org/2016/09/18/20200/politics-pain-drugmakers-foughtstate-opioid-limits-amid-crisis. Accessed December 1, 2019.
Centers for Disease Control and Prevention (CDC). 2019a. Prescribing practices: Changes in opioid prescribing practices. https://www. cdc.gov/drugoverdose/data/prescribing/prescribing-practices.html. Accessed December 1, 2019.

. 2019b. Opioid data analysis and resources. https://www. cdc.gov/drugoverdose/data/analysis.html. Accessed December 1, 2019.

Chambers, T. 2017. The illusion of transparency. American Journal of Bioethics 17(6): 32-33.

Collins, F.S. 2017. Statement from NIH director on combating opioid crisis with scientific solutions. NIH.gov, October 26. https://www.nih.gov/about-nih/who-we-are/nihdirector/statements/statement-nih-director-combatingopioid-crisis-scientific-solutions. Accessed December 1, 2017.

. 2018. Statement from NIH Director on public-private partnerships as part of the NIH HEAL initiative. NIH.gov, April 13. https://www.nih.gov/about-nih/who-we-are/nihdirector/statements/statement-public-private-partnershipspart-nih-heal-initiative. Accessed December 1, 2019.

Clark, K., and H. Rogers. 2019. Corporate influence: Purdue and the WHO. Offices of the U.S. Representatives Katherine Clark and Hal Rogers, May 22. https://katherineclark. house.gov/_cache/files/a/a/aaa7536a-6db3-4192-b943-364 e7c599d10/818172D42793504DD9DFE64B77A77C0 E.5.22.19-who-purdue-report-final.pdf. Accessed May 31, 2019.

Corkery, M., and K. Thomas. 2018. Drug industry wages opioid fight using an anti-addiction ally. New York Times, February 2. https://www.nytimes.com/2018/02/08/business/opioidsaddiction-pharma.html. Accessed December 1, 2019.

Council of Economic Advisors (CEA). 2017. The underestimated costs of the opioid crisis. Washington D.C.: Office of the President of the United States. https://www.whitehouse. gov/sites/whitehouse.gov/files/images/The\%20 Underestimated $\% 20$ Cost $\% 20$ of $\% 20$ the $\% 20$ Opioid $\% 20$ Crisis.pdf. Accessed December 1, 2019.

- 2019. The full cost of the opioid crisis: $\$ 2.5$ trillion over four years. Washington D.C.: Office of the President of the United States. https://www.whitehouse.gov/articles/full-costopioid-crisis-2-5-trillion-four-years/. Accessed December 16, 2019.

Emanuel, G., and K. Thomas. 2019. Top executives of Insys, an opioid company, are found guilty of racketeering. New York Times, May 2. https://www.nytimes.com/2019/05/02 /health/insys-trial-verdict-kapoor.html. Accessed May 31, 2019.

Farzan, A.N. 2020. A tech company gave doctors free softwarerigged to encourage them to prescribe opioids, prosecutors say. Washington Post, January 28. https://www. washingtonpost.com/nation/2020/01/28/opioid-kickbacksoftware/. Accessed February 1, 2020.

Freudenberg, N. 2014. Lethal but legal: Corporations, consumption, and protecting public health. New York: Oxford University Press.

Gluck, A.R., A. Hall, and G. Curfman. 2018. Civil litigation and the opioid crisis: The role of courts in a national health crisis. Journal of Law, Medicine, and Ethics 46(2): 351-366.

Goldberg, D.S. 2019. The Shadows of sunlight: Why disclosure should not be a priority in addressing conflicts of interest. Public Health Ethics 12(2): 202-212. 
Gonzales, R. 2019. Drug distributor and former execs face first criminal charges in opioid crisis. NPR, April 23. https://www.npr.org/2019/04/23/716571375/drugdistributor-and-former-execs-face-first-criminal-charges-inopioid-crisis. Accessed December 1, 2019.

Gornall, J. 2015. Sugar: A web of influence. BMJ 350: h231.

Greene, J.A., and S.H. Podolsky. 2009. Keeping modern in medicine: Pharmaceutical promotion and physician education in postwar America. Bulletin of the History of Medicine 83(2): 331-377.

Hadland, S.E., M.S. Krieger, and B.D.L. Marshall. 2017. Industry payments to physicians for opioid products, 2013-2015. American Journal of Public Health 107(9): 1493-1495.

Hadland, S.E., M. Cerdá, Y. Li, M.S. Krieger, and B.D.L. Marshall. 2018. Association of pharmaceutical industry marketing of opioid products to physicians with subsequent opioid prescribing. JAMA Internal Medicine 178(6): 861863.

Hadland, S.E., A. Rivera-Aguirre, and B.D.L. Marshall. 2019. Association of Pharmaceutical Industry marketing of opioid products with mortality from opioid-related overdoses. JAMA Open 2019(1): e186007.

Hals, T. 2019a. OxyContin maker Purdue Pharma to pay states' lawyers, urged to help victims. New York Times, November 21. https://www.nytimes.com/reuters/2019/11/20 /business/20reuters-purdue-pharma-bankruptcy.html. Accessed December 1, 2019.

- 2019b. Bankrupt Insys reaches deal to divvy cash among opioid victims. New York Times, November 21. https://www. nytimes.com/reuters/2019/11/21/us/21reuters-insys-opioidsbankruptcy.html. Accessed December 1, 2019.

Hoffman, J. 2019a. Johnson \& Johnson ordered to pay $\$ 572$ million in landmark opioid trial. New York Times, August 26. https://www.nytimes.com/2019/08/26/health/oklahomaopioids-johnson-and-johnson.html. Accessed August 27, 2019.

- 2019b. Whoops. Judge reduces J\&J opioid fine after mistaking thousands for millions. New York Times, November 15. https://www.nytimes.com/2019/11/15 /health/opioids-oklahoma-johnson-fine.html. Accessed December 1, 2019.

- 2019c. \$260 million opioid settlement reached at last minute with big drug companies. New York Times, October 21. https://www.nytimes.com/2019/10/21/health/opioidsettlement.html. Accessed October 22, 2019.

- 2019d. Drug giants close in on a $\$ 50$ billion settlement of opioid cases. New York Times, October 19. https://www. nytimes.com/2019/10/16/health/opioids-settlementdistributors.html. Accessed October 20, 2019.

- 2020a. Payout from a national opioids settlement won't be as big as hoped. New York Times, February 17. https:/www.nytimes.com/2020/02/17/health/nationalopioid-settlement.html. Accessed March 14, 2020.

- 2020b. Opioid settlement offer provokes clash between states and cities. New York Times, March 13. https://www. nytimes.com/2020/03/13/health/opioids-settlement.html. Accessed March 14, 2020.

Hollander, M., J.M. Donohue, B.D. Stein, and E.E. Krans. 2019. Association between opioid prescribing in Medicare and pharmaceutical company gifts by physician specialty.
Journal of General Internal Medicine. https://doi. org/10.1007/s11606-019-05470-0.

Homeland Security and Government Affairs Committee (HSGAC). 2018a. Fueling an epidemic-Report Two: Exposing financial ties between opioid manufacturers and third party advocacy groups. Washington, D.C.: U.S. Senate. https://www.hsdl.org/?view\&did=808171. Accessed December 1, 2019.

- 2018b. Fueling an epidemic-Report Four: Inside the Insys strategy for boosting fentanyl sales. Washington D.C.: U.S. Senate. https://www.hsdl.org/?view\&did=818447. Accessed December 1, 2019.

Horwitz, S., S. Higham, D. Bennett, and M. Kornfield. 2019. Inside the opioid industry's marketing machine: Unsealed court documents reveal how drug companies ramped up sales during the epidemic, Washington Post, December 6. https://www.washingtonpost.com/graphics/2019 /investigations/opioid-marketing/. Accessed December 7, 2019.

Joseph, A. 2019a. "A blizzard of prescriptions": Documents reveal new details about Purdue's marketing of OxyContin. STAT, January 15. https://www.statnews.com/2019/01/15 /massachusetts-purdue-lawsuit-new-details/. Accessed December 1, 2019.

- 2019b. Purdue cemented ties with universities and hospitals to expand opioid sales, documents contend. STAT, January 16. https://www.statnews.com/2019/01/16/purduepharma-cemented-ties-to-universities-hospitals/. Access December 1, 2019.

- 2019c. "We owe much to the Sackler family": How gifts to a top medical school advanced the interests of Purdue Pharma. STAT, April 9. https://www.statnews.com/2019/04 /09/sackler-purdue-pharma-gifts-to-tufts-advancedcompany-interests/. Accessed December 1, 2019.

Kanter, G.P. 2018. Extending the Sunshine Act from physicians to patient advocacy organizations. AJPH 108(8): 978-979.

Kanter, G.P., and G. Loewenstein. 2019. Evaluating open payments. JAMA 322(5): 401-402.

Kanter, G.P., D. Carpenter, L. Lehmann, and M. Mello. 2019. Effect of the public disclosure of industry payments information on patients: Results from a population-based natural experiment. BMJ Open, no. 024020.

Kaplan, S. and J. Hoffman. 2020. Mallinckrodt reaches \$1.6 billion deal to settle opioid lawsuits. New York Times, February 25. http://www.nytimes.com/2020/02/25 /health/mallinckrodt-opioid-settlement.html. Accessed March 14, 2020.

Keefe, P.R. 2017. The family that built an empire of pain. New Yorker, October 30. 3449.

Kinetz, E. 2019. Fake doctors, pilfered medical records drive Oxy China sales. Associated Press, November 20. https://apnews. com/4122af46fdba42119ae3db30aa13537c. Accessed December 1, 2019.

Lesser, B., D. Levine, L. Girion, and J. Dowdell. 2019. How judges added to the grim toll of opioids. Reuters.com, June 25. https://www.reuters.com/investigates/specialreport/usa-courts-secrecy-judges/. Accessed December 1, 2019.

Lessig, L. 2015. Republic, lost: The corruption of equality and the steps to end it. New York: Twelve. 
Lin, D.H., E. Lucas, I.B. Murimi, et al. 2017. Financial conflicts of interest and the Centers for Disease Control and Prevention's 2016 guideline for prescribing opioids for chronic pain. JAMA Internal Medicine 177(3): 427-428.

Lo, B., and M. Field. 2009. Conflict of interest in medical research, education, and practice. Washington, D.C.: National Academies Press.

Lo, B., and D. Grady. 2017. Payments to physicians: Does the amount of money make a difference? JAMA 317(17): 17191720 .

Loewenstein, G., D.M. Cain, and S. Sah. 2011. The limits of transparency: Pitfalls and potential of disclosing conflicts of interest. American Economic Review 101(3): 423-428.

Loewenstein, G., S. Sah, and D. Cain. 2012. The unintended consequences of conflict of interest disclosure. JAMA 307(7): 669-670.

Lundh A., J. Lexchin, B. Mintzes, J. Schroll, and L. Bero. 2017. Industry sponsorship and research outcome. Cochrane Database of Systematic Reviews. Issue 2. Art. No.: MR000033.

Macy, B. 2018. Dopesick: dealers, doctors, and the drug company that addicted America. New York: Little, Brown \& Co.

Marks, J.H. 2017. Caveat partner: Sharing responsibility for health with the food industry. American Journal of Public Health 107(3): 360-361.

. 2019a. The Perils of partnership: Industry influence, institutional integrity, and public health. New York: Oxford University Press.

- 2019b. Opioid crisis shows partnering with industry can be bad for public health. The Conversation, March 6 . $\mathrm{https}$ ://theconversation.com/opioid-crisis-shows-partneringwith-industry-can-be-bad-for-public-health-112649. Accessed December 1, 2019.

. 2019c. Are corporations nudging the nudgers? American Journal of Bioethics 19(5): 70-72.

2020. Beyond disclosure: Developing law and policy to tackle corporate influence. American Journal of Law and Medicine 46 (forthcoming). https://doi.org/10.1177 /0098858820933499.

McCoy, M.S., M. Carniol, K. Chockley, J.W. Urwin, E.J. Emanuel, and H. Schmidt. 2017. Conflict of interest for patient advocacy organizations. New England Journal of Medicine 376: 880-885.

McCoy, M.S. 2018. Industry support of patient advocacy organizations: The case for an extension of the Sunshine Act provisions of the Affordable Care Act. American Journal of Public Health 108(8): 1026-1030.

McCoy, M.S., and G.P. Kanter. 2018. Campaign contributions from political action committees to members of congressional committees responding to the opioid crisis. JAMA 320(14): 1489-1491.

McGreal, C. 2018. American overdose: The opioid tragedy in three acts. New York: Hachette.

- 2019. US medical group that pushed doctors to prescribe painkillers forced to close. The Guardian, May 25. https://www.theguardian.com/us-news/2019/may/25 /american-pain-society-doctors-painkillers. Accessed May 31, 2019.

McNeil, H. 2019. UB renames structure "Pharmacy Building" after removing convicted alumnus' name. The Buffalo News, June 20. https://buffalonews.com/2019/06/20/ub- renames-structure-pharmacy-building-after-removingconvicted-alumnus-name/. Accessed December 1, 2019.

Meier, B. 2007. In guilty plea, OxyContin maker to pay $\$ 600$ million. New York Times, May 10. https://www.nytimes. com/2007/05/10/business/11drug-web.html. Accessed December 1, 2018.

- 2018. Pain killer: An empire of deceit and the origin of America's opioid epidemic. New York: Random House.

Michaels, D. 2008. Doubt is our product: How industry's assault on science threatens your health. New York: Oxford University Press.

- 2020. The triumph of doubt: Dark money and the science of deception. New York: Oxford University Press.

National Institutes of Health (NIH) Working Group. 2018. Ethical considerations for industry partnership on research to help end the opioid crisis: Draft report. March 20. Washington, D.C.: National Institutes of Health. https://acd.od.nih. gov/documents/presentations/032018_opioids-draft-report. pdf. Accessed December 1, 2019.

- 2019. HEAL Initiative: News and Events. https://heal. nih.gov/news. Accessed December 1, 2019.

Ornstein, C., and K. Thomas. 2018. What these medical journals don't reveal: Top doctors' ties to industry. New York Times, December 8. https://www.nytimes.com/2018/12/08 /health/medical-journals-conflicts-of-interest.html. Accessed December 31, 2018.

Ornstein, C., and T. Weber. 2012. American Pain Foundation shuts down as Senators launch investigation of prescription narcotics. Propublica, May 8. https://www.propublica. org/article/senate-panel-investigates-drug-company-ties-topain-groups. Accessed December 1, 2019.

Pharmaceutical Research and Manufacturers of America (PhRMA). 2017. PhRMA announces major commitment to address the opioid crisis in America. Press release, December 12. https://www.phrma.org/press-release/phrma-announcesmajor-commitment-to-address-the-opioid-crisis-in-america. Accessed December 1, 2019.

Podolsky, S.H. 2015. The antibiotic era: Reform, resistance, and the pursuit of a rational therapeutics. Baltimore: Johns Hopkins University Press.

Podolsky, S.H, D. Hertzberg, and J.A. Greene. 2019. Preying on prescribers (and their patients) - Pharmaceutical marketing, iatrogenic epidemics, and the Sackler legacy. New England Journal of Medicine 380(19): 1785-1787.

Poston, B. 2018. Capping years of criticism, Purdue Pharma will stop promoting its opioid drugs to doctors. Los Angeles Times, February 10. https://www.latimes.com/local/lanow/la-me-lnpurdue-marketing-20180210-story.html. Accessed December 1, 2019.

Purdue Pharma. 2018. We manufacture prescription opioids. How could we not help fight the prescription and illicit opioid abuse crisis? New York Times, January 2. http://bit. ly/PurduePartnerAd. Accessed January 31, 2018.

Quinones, S. 2006. Dreamland: The true tale of America's opiate epidemic. New York: Bloomsbury.

Raymond, N. 2019. Judge partly vacates convictions of opioid maker Insys' founder, executives. New York Times, November 26. https://www.nytimes.com/reuters/2019/11/26 /us/26reuters-insys-opioids.html. Accessed November 27, 2019. 
Relman, A.S. 1980. The new medical-industrial complex. New England Journal of Medicine 303(17): 963-970.

. 1984. Dealing with conflicts of interest. New England Journal of Medicine 310(18): 1182-1183.

Richardson, E. 2014. Health policy brief: The Physician Payments Sunshine Act. Health Affairs, October 2. https://www. healthaffairs.org/do/10.1377/hpb20141002.272302/full/. Accessed December 1, 2019.

Rodwin, M. 2018. Attempts to redefine conflicts of interest. Accountability in Research 25(2): 67-78.

Rose, S.L. 2013. Patient advocacy organizations: Institutional conflicts of interest, trust, and trustworthiness. Journal of Law, Medicine, and Ethics 41(3): 680-687.

Rose, S.L., J. Highland, M.T. Karafa, and S. Joffe. 2017. Patient advocacy organizations, industry funding, and conflicts of interest. JAMA Internal Medicine 177(3): 344-350.

Rose, S.L., S. Sah, R. Dweik, et al. 2019. Patient responses to physician disclosures of industry conflicts of interest: A randomized field experiment. Organizational Behavior and Human Decision Processes. https://doi.org/10.1016/j. obhdp.2019.03.005.

Ross, C. 2019. Purdue's Richard Sackler proposed plan to play down OxyContin risks, and wanted drug maker feared "like a tiger," files show. STAT News, December 2. https://www. statnews.com/2019/12/02/purdue-richard-sackler-proposedplan-play-down-oxycontin-risks/. Accessed December 1, 2019.

Ross, J., K. Hill, D. Egilman, and H. Krumholz. 2008. Guest authorship and ghostwriting in publications related to Rofecoxib: A case study of industry documents from Rofecoxib litigation. JAMA 299(15): 1800-1812.

Ryan, S., L. Girion, and S. Glover. 2016. OxyContin goes global-"We're only just getting started." Los Angeles Times, December 18. https://www.latimes.com/projects/la-meoxycontin-part3/. Accessed December 1, 2019.

Sah, S. 2016. The paradox of disclosure. New York Times, July 8. https://www.nytimes.com/2016/07/10/opinion/sunday/theparadox-of-disclosure.html. Accessed December 1, 2019.

. 2019. Conflict of interest disclosure as a reminder of professional norms: Clients first! Organizational Behavior and Human Decision Processes 154: 62-79.

Sah, S., and A. Fugh-Berman. 2013. Physicians under the influence: Social psychology and industry marketing strategies. Journal of Law, Medicine, and Ethics 41(3): 665-672.

Sah, S., G. Loewenstein, and D. Cain. 2019. Insinuation anxiety: Concern that advice rejection will signal distrust after conflict of interest disclosure. Personal and Social Psychology Bulletin 45(7): 1099-1112.

Schulte, F. 2018. Purdue Pharma edits public service ad in Washington Post. Washington Post, July 24. https://www. washingtonpost.com/national/health-science/purduepharma-edits-public-service-ad-in-washington-post/2018/07 /24/2f1ddefc-8f7c-11e8-ae59-01880eac5f1d_story.html. Accessed December 1, 2019.

Schwab, T. 2019. US opioid prescribing: The federal government advisers with recent ties to big pharma. BMJ 366: I5167.

Silverman, E. 2019. Teva reaches $\$ 85$ million settlement on eve of opioid trial in Oklahoma. STAT News, May 26. https://www. statnews.com/pharmalot/2019/05/26/teva-opioid-oklahomatrial-settlement/. Accessed May 27, 2019.

Sismondo, S. 2018. Ghost-managed medicine: Big pharma's invisible hands. Manchester, U.K.: Mattering Press.

Steinman, M., L. Bero, M. Chren, and C. Landefeld. 2006. Narrative review: The promotion of gabapentin: An analysis of internal industry documents. Annals of Internal Medicine 145(4): 284-293.

Thomas, K. 2019. Insys, the opioid drug maker, to pay $\$ 225$ million to settle fraud charges. New York Times, June 5. https://www.nytimes.com/2019/06/05/health/insys-opioidfentanyl-settlement.html. Accessed June 6, 2019.

. 2020. Insys Founder Gets 51/2 Years in Prison in Opioid Kickback Scheme. New York Times, January 23. https://www.nytimes.com/2020/01/23/health/opioids-insyskapoor-prison.html. Accessed January 24, 2020.

Volkow, N., and F.S. Collins. 2017. The role of science in addressing the opioid crisis. New England Journal of Medicine 377(4): 391-394.

Woodson, C. 2019. Stripper turned pharma executive gave doctor a lap dance to get him to prescribe drug, officials say. Washington Post, January 30. https://www.washingtonpost. com/business/2019/01/30/stripper-turned-pharma-execgave-doctor-lap-dance-get-him-prescribe-drugs-officialssay/?utm_term=.6a5e1ba00c20. Accessed February 1, 2019.

World Health Organization (WHO). 2011. Ensuring balance in national policies on controlled substances: Guidance for availability and accessibility of controlled medicines. https://www.who.int/medicines/areas/quality_safety/GLs Ens_Balance_NOCP_Col_EN_sanend.pdf. Accessed January $31,20 \overline{1} 8$.

- 2012. Guidelines on the pharmacological treatment of persisting pain in children with medical illnesses. Geneva: WHO. https://apps.who.int/iris/bitstream/handle/10665 /44540/9789241548120_Guidelines.pdf. Accessed January $31,2018$.

. 2019. Web statement on pain management guidance. June 20. https://www.who.int/medicines/areas/quality_ safety/guide_on_pain/en/. Accessed June 20, 2019.

Young, I.M. 2011. Responsibility for justice. New York: Oxford University Press.

Yurko, S., and Remz, P.C. 2019. Report and recommendations concerning the relationship of the Sackler family and Purdue Pharma with Tufts University. https://president.tufts.edu/wpcontent/uploads/Final-Report-Tufts-Sackler-and-PurduePharma-December-2019.pdf. Accessed December 16, 2019.

Zezima, K., and Bernstein, L. 2019. "Hammer on the abusers": Mass. attorney general alleges Purdue Pharma tried to shift blame for opioid addiction. Washington Post, January 15. https://www.washingtonpost.com/national/hammer-on-theabusers-mass-attorney-general-alleges-purdue-pharma-triedto-shift-blame-for-opioid-addiction/2019/01/15/4af25c4c190c-11e9-88fe-f9f77a3bcb6c_story.html. Accessed December 1, 2019.

Publisher's note Springer Nature remains neutral with regard to jurisdictional claims in published maps and institutional affiliations. 